\title{
The Effect of Estrogen on
}

\section{Bile Formation in the Rat}

\author{
E. L. FORKER \\ From the Department of Physiology and Biophysics and the Gastroenterology \\ Research Laboratories, Department of Medicine, University of Iowa, \\ Iowa City, Iowa 52240
}

\begin{abstract}
A в S T R A C T Female rats given large doses of estrone developed increased permeability of the biliary tree as determined by an increase in the biliary clearances of sucrose and mannitol. Spontaneous bile flow and the choleretic response to dehydrocholate declined. Estrone reduced the clearance of sulfobromophthalein (BSP) at low plasma concentrations as well as the absolute rate of BSP excretion when plasma levels were above those required to saturate active transport. The findings are consistent with a postulate that estrogen cholestasis may involve enhanced diffusion of materials from bile to blood in addition to inhibition of active transport in the opposite direction.
\end{abstract}

\section{INTRODUCTION}

Sporadic occurrence of recurrent jaundice and/or pruritus in the last trimester of pregnancy (1-3), abnormal removal of sulfobromophthalein (BSP) during otherwise uncomplicated pregnancy $(4,5)$, and the predisposition of multiparous women to form gallstones all point to a possible association between high levels of circulating estrogen and altered bile formation. Scattered reports (6-9) of cholestasis following the use of oral contraceptives have heightened this suspicion as have recent suggestions (10-12), that impaired hepatic excretion in the newborn may reflect, at least in part, a deleterious effect of maternal estrogen on the fetus. However one regards the circumstantial evidence implicating sex hormones in these clinical situations, it is clear that large doses of estrogen regularly impair BSP excretion in both rats $(13,14)$ and people $(10,15)$. Among a variety of natural and synthetic estrogens which share this capacity in the rat, estrone is reported to be most active (13). Judging from the observation

Dr. Forker is a Markle Scholar in Academic Medicine.

Received for publication 19 August 1968 and in revised form 22 October 1968. that conjugation with glutathione is normal under these circumstances, while the maximum rate of BSP excretion is reduced, it is probable that estrogens interfere primarily with the processes responsible for excreting BSP and its conjugates into bile rather than with the delivery of BSP to the hepatic parenchyma or with its intracellular metabolism. Beyond this, however, nothing is known about the underlying mechanism of the estrogen effect.

This is a report of experiments designed to explore the possibility that changes in passive permeability of the canalicular membrane might help to explain the effect of estrone on bile formation in rats. The specific hypothesis is as follows. To the extent that reduced excretion of BSP is attributable to increased diffusion of BSP from bile to plasma rather than to impaired active transport of BSP in the opposite direction, this effect should be observable as enhanced excretion of inert solutes assumed to enter bile passively. As predicted by this hypothesis, biliary clearances of radioactive mannitol and sucrose increased after treatment with estrone, whereas bile flow and BSP excretion declined. Possible interpretations of these findings are discussed in light of assumptions about the site of the estrogen effect and the normal pathway for biliary excretion of inert solutes.

\section{METHODS}

Virgin female Sprague-Dawley rats (250 $\mathrm{g}$ body weight) received seven daily subcutaneous injections of estrone (2.5 $\mathrm{mg}$, Sigma Chemical Corp.) dissolved in propylene glycol $(0.5 \mathrm{ml})$. Control rats received identical volumes of propylene glycol alone. Total dose and method of administration were similar to those employed by Gallagher, Mueller, and Kappas (13) except that the solubilizing agent, $N, N$-dimethylacetamide, was omitted in favor of warming the solution before injection. Experiments were conducted alternately with estrone-treated rats and controls fasted for $18 \mathrm{hr}$ after the last injection. After anesthesia with intraperitoneal allobarbital and urethane (Dial-urethane, Ciba), the renal pedicles were ligated and small polyethylene catheters in- 
TABLE I

Organ Weight and Bile Flow

\begin{tabular}{|c|c|c|c|c|c|c|}
\hline & \multicolumn{2}{|c|}{ Body wt } & \multicolumn{2}{|c|}{ Bile flow } & \multicolumn{2}{|c|}{ Organ wt } \\
\hline & Initial & $\%$ change & Spontaneous & $\begin{array}{l}\text { Change with } \\
\text { dehydrocholate }\end{array}$ & Liver & Uterus \\
\hline Control & \multicolumn{2}{|c|}{ g } & \multicolumn{2}{|c|}{$\mu l \min ^{-1}$} & \multicolumn{2}{|c|}{$g$} \\
\hline Mean & 243 & -1 & 11.6 & 26.6 & 6.12 & 0.7 \\
\hline $95 \%$ c.i. & 4 & 2 & 0.9 & 4.3 & 0.28 & 0.1 \\
\hline $\mathrm{n}$ & 20 & 20 & 20 & 11 & 20 & 20 \\
\hline \multicolumn{7}{|l|}{ Estrone } \\
\hline Mean & 243 & -13 & 7.8 & 18.1 : & 7.84 & 2.4 \\
\hline $95 \%$ c.i. & 4 & 2 & 0.6 & 2.7 & 0.48 & 0.5 \\
\hline $\mathrm{n}$ & 22 & 22 & 22 & 14 & 22 & 22 \\
\hline \multicolumn{7}{|l|}{ Difference } \\
\hline |Mean| & 0 & 12 & 3.8 & 8.5 & 1.72 & 1.7 \\
\hline $99 \%$ c.i. & NS & 4 & 1.4 & 6.2 & 0.74 & 0.7 \\
\hline
\end{tabular}

c.i. $=$ confidence interval $; \mathrm{NS}=$ not significant $(\mid$ mean $\mid<c . i.) ; n=$ number of experiments.

serted in a jugular vein and the comon bile duct at the liver hilus. Rectal temperature was maintained between $37^{\circ}$ and $38^{\circ} \mathrm{C}$. Fluid lost from the bile fistula was replaced by a continuous infusion of $2.5 \%$ glucose, $0.4 \% \mathrm{NaCl}$ solution. Stability of bile flow was monitored continuously with a photoelectric drop counter and collected volumes estimated by weight.
Depending on the experiment to be conducted, rats received a single intravenous injection of sucrose $-{ }^{14} \mathrm{C}(4 \mu \mathrm{c}$, New England Nuclear Corp.), mannitol- ${ }^{3} \mathrm{H}(20 \mu \mathrm{c}$, New England Nuclear Corp.), ${ }^{131}$ I-labeled human serum albumin (1 $\mu \mathrm{c}$, Abbott Laboratories), or BSP (60 mg kg-1, Hynson, Westcott \& Dunning, Inc., Baltimore, Md.). When steadystate BSP clearance was measured, the single injection was

TABLE II

Steady-State BSP Excretion

\begin{tabular}{|c|c|c|c|c|c|}
\hline & Plasma & Bile:plasma ratio & Clearance & Bile flow & Liver wt \\
\hline & $m g \%$ & & $m l \min ^{-1}$ & $\mu l \min ^{-1}$ & 8 \\
\hline \multirow[t]{3}{*}{ Control* } & 2.27 & 368 & 4.1 & 11.2 & 6.65 \\
\hline & 1.75 & 406 & 5.6 & 13.8 & 7.65 \\
\hline & 1.98 & 390 & 4.3 & 10.9 & 6.77 \\
\hline Mean & 2.00 & 388 & 4.7 & 12.0 & 7.02 \\
\hline \multirow[t]{3}{*}{ Estrone* } & 4.36 & 254 & 2.2 & 8.8 & 9.22 \\
\hline & 3.69 & 321 & 2.5 & 7.8 & 8.88 \\
\hline & 3.02 & 328 & 3.2 & 9.7 & 10.02 \\
\hline Mean & 3.69 & 301 & 2.5 & 8.8 & 9.37 \\
\hline \multirow[t]{3}{*}{ Controlł } & 0.84 & 578 & 5.3 & 9.2 & 6.66 \\
\hline & 0.73 & 742 & 6.3 & 8.5 & 6.1 .1 \\
\hline & 0.85 & 511 & 5.1 & 9.9 & 5.96 \\
\hline Mean & 0.81 & 610 & 5.6 & 9.2 & 6.24 \\
\hline \multirow[t]{3}{*}{ Estrone } & 1.85 & 366 & 2.4 & 6.7 & 6.92 \\
\hline & 1.17 & 394 & 2.7 & 6.9 & 8.30 \\
\hline & 1.25 & 460 & 2.8 & 6.1 & 7.74 \\
\hline Mean & 1.42 & 407 & 2.6 & 6.6 & 7.65 \\
\hline
\end{tabular}

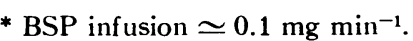

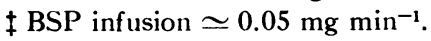




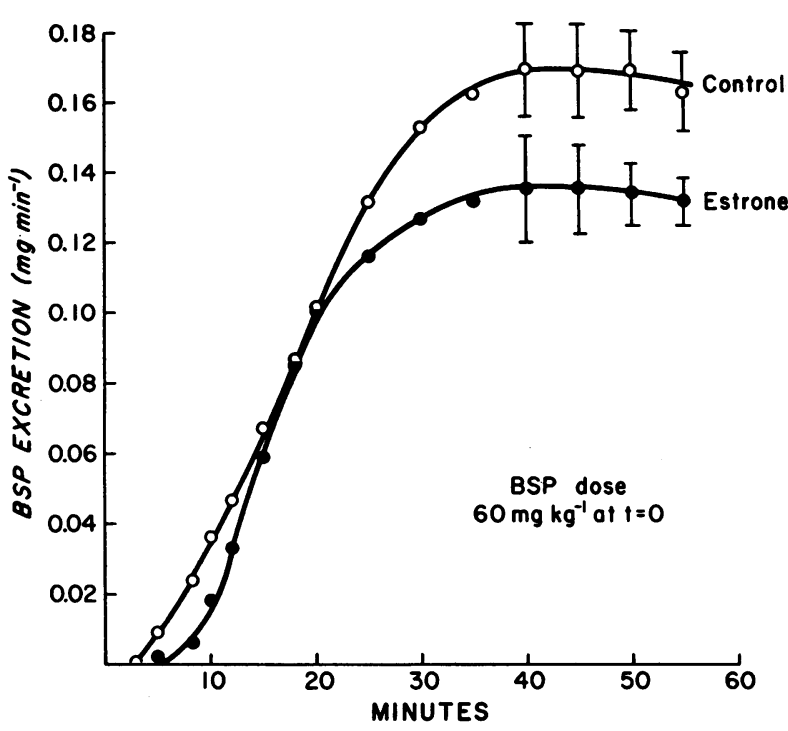

FIgURE 1 The time course of BSP excretion after intravenous injection of $60 \mathrm{mg} \mathrm{kg}^{-1}$ to saturate excretory transport. Mean values $\pm S E, n=5$ for each curve.

replaced by a continuous $2 \mathrm{hr}$ infusion of BSP dissolved in $0.9 \% \mathrm{NaCl}$ solution. Steady-state clearances of mannitol and sucrose were measured $2.5-3 \mathrm{hr}$ after injection and in some rats again after a stable maximum choleresis was produced by infusing sodium dehydrocholate (Dome Chemicals, Inc., New York) for an additional $40 \mathrm{~min}$ at a rate of $0.6 \mathrm{mg}$ $\min ^{-1}$. Concentrations of labeled albumin in plasma and liver tissue were determined $20 \mathrm{~min}$ after injection. Blood was obtained during an experiment by cutting the tip of the tail or, at the end of an experiment, from the abdominal aorta. To minimize variations in liver weight all rats were exsanguinated.

Concentrations of sucrose and mannitol were determined in a liquid scintillation counter after dissolving 20-50 $\mu 1$ of plasma, bile, or the supernatant fluid from liver homogenate in Bray's solution (16). Small corrections required for variable quenching were determined by internal standardization. Liver homogenates were prepared by grinding approximately half of the liver with $10 \mathrm{ml}$ of $3 \%$ trichloracetic acid in a microhomogenizer (Ivan Sorvall, Inc., Norwalk, Conn.). Radioactivity in liver water was calculated from the activity in the supernatant and the fractional water content of the liver measured by drying the remaining half to constant weight. Radioactivity from ${ }^{131} \mathrm{I}$ was counted directly in liver tissue with a NaI crystal. BSP was measured by the method of Seligson, Marino, and Dodson (17) in a Beckman DU spectrophotometer at $580 \mathrm{~m} \mu$. $\mathrm{Na}^{+}$and $\mathrm{K}^{+}$ were determined by flame photometry. Plasma concentrations of total and direct reacting bilirubin, glutamic-oxalacetic transaminase, and alkaline phosphatase were determined, respectively, according to the methods of Malloy and Evelyn (18), Reitman and Frankel (19), and Bessey, Lowrey, and Brock (20).

Unless otherwise noted, results are expressed as the mean value \pm the $95 \%$ confidence interval. Statistical significance is indicated by citing the value of $P$ determined by Student's $t$ test or the $99 \%$ confidence interval for the difference between mean values (21).

\section{RESULTS}

The large dose of estrone employed in these experiments led to a moderate loss of body weight, an increase in liver weight, and striking enlargement of the uterus. Estrone-treated rats appeared healthy, however, and except for diminished bile flow could not be distinguished by inspection from rats that received propylene glycol alone. The changes in organ weight and bile flow are summarized in Table I.

The results of two studies in which BSP was given by continuous infusion at nominal rates of 0.1 or 0.05 $\mathrm{mg} \mathrm{min} \mathrm{m}^{-1}$ appear in Table II. After $2 \mathrm{hr}$ biliary excretion of BSP was approximately $85 \%$ of the infusion rate in both estrone-treated rats and controls. Doubling the rate of BSP infusion caused a similar increase in bile flow in both groups, but this procedure did not produce significant changes in plasma clearance. Mean values for six determinations of clearance were $50 \%$ less in es-

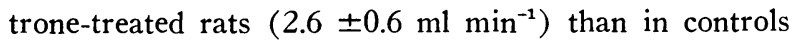
$\left(5.1 \pm 1.3 \mathrm{ml} \mathrm{min}^{-1}\right)$. The decline in clearance was associated with mean decrements of $20 \%$ in bile flow and $30 \%$ in bile: plasma concentration ratio.

Five additional rats given estrone and five controls received a single injection of BSP $\left(60 \mathrm{mg} \mathrm{kg}^{-1}\right)$ to saturate the active transport of this dye. The time course of BSP excretion after this procedure is shown in Fig. 1. Peak excretion occurred in both groups after $40 \mathrm{~min}$ and remained virtually constant during the next $15 \mathrm{~min}$.

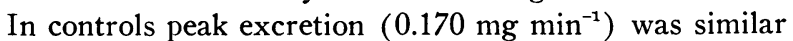
to a previously reported value for "transport maximum" in normal rats determined by a continuous infusion method (22). Peak excretion by estrone-treated rats was $20 \%$ lower $(P<0.05)$. This change was associ-

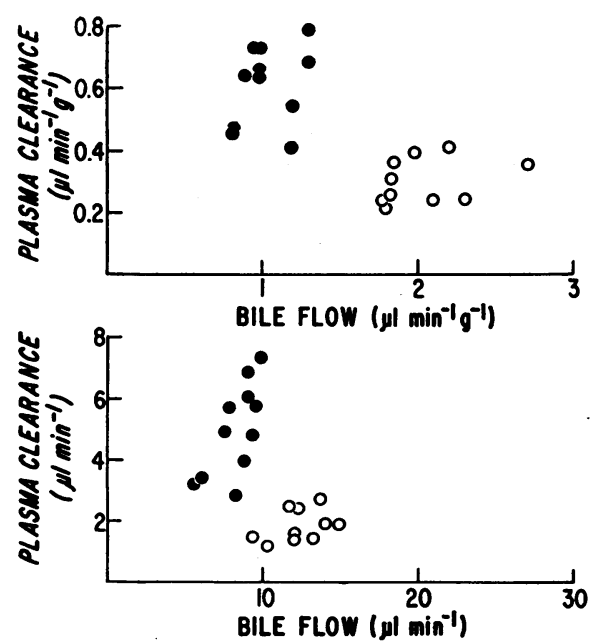

Figure 2 Sucrose clearance and spontaneous bile flow before and after division by wet liver weight. Estrone $(\bullet)$; control $(\mathrm{O})$. 
ated with mean decrements of $12 \%$ in bile flow and $8 \%$ in BSP concentration. In both Fig. 1 and in Table II the rates of BSP excretion, plasma clearance, and bile flow have been expressed in absolute terms. Since in each case liver weights in the control group were less than those in the group receiving estrone, expressing the results as rates per gram of liver has the effect of exaggerating the differences.

The effect of estrone on sucrose clearance during spontaneous bile flow is presented in Fig. 2. The same results are given in two ways to illustrate the effect of normalizing the data to take account of differences in liver weight. Dividing by liver weight exaggerates the differences in bile flow while diminishing the differences in plasma clearance, but in either case it is clear that sucrose clearance was on the average at least twice as fast in rats receiving estrone as in controls, despite an opposite change in bile flow.

Fig. 3 shows the effect of estrone on the bile: plasma concentration ratio for sucrose during spontaneous flow and dehydrocholate choleresis. In control rats this ratio was approximately 0.14 over a four-fold range of bile flow, but in rats given estrone, choleresis led to an abrupt fall in this ratio from an average value of 0.56 to levels approaching those observed in the control group. Concentration ratios in Fig. 3 are plotted against bile flow per gram of liver weight to emphasize that the maximum choleretic response of estrone-treated rats was uniformly less than that of the control group. Though less pronounced, the same effect was evident from a comparison of mean increments in bile flow without regard to liver weight (Table I).

When a smaller solute, mannitol, was used to assess permeability changes, the effect of estrone was apparent only during choleresis. Results from 11 experi-

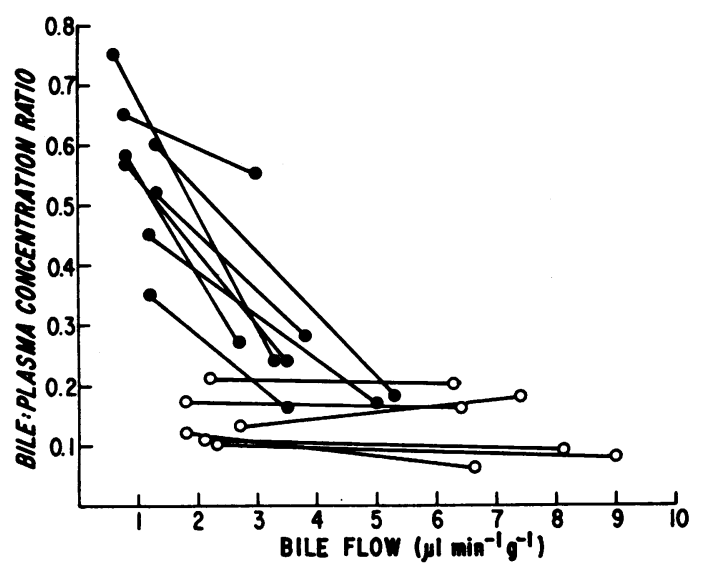

FIGURE 3 Sucrose bile: plasma concentration ratios during spontaneous bile flow and dehydrocholate choleresis. Lines connect points determined in one rat. Estrone $(\bullet)$; control (O).

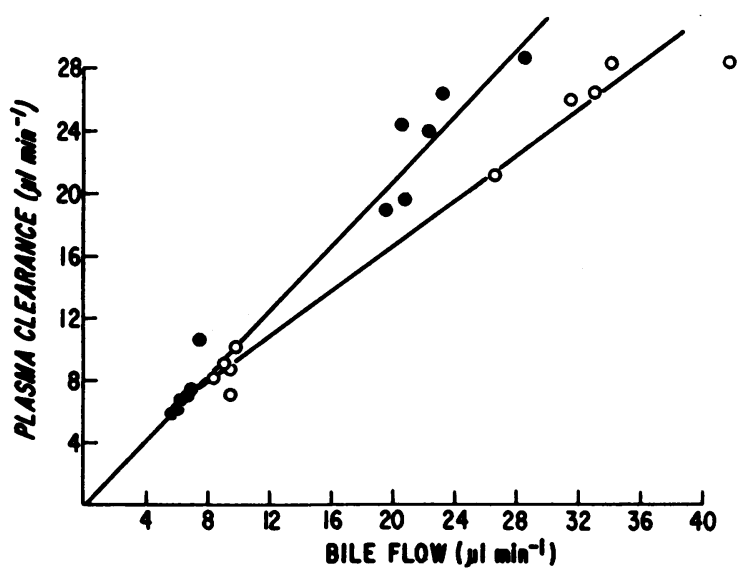

Figure 4 Mannitol clearance during spontaneous bile flow and dehydrocholate choleresis. Mean slopes are shown for each group. See Table III for individual values. Estrone (•) ; control (O).

ments are illustrated in Fig. 4. During spontaneous bile flow mannitol clearance was nearly identical to bile flow in both groups. During choleresis, however, mannitol clearance was approximately $20 \%$ less than bile flow in the control group, whereas rats given estrone maintained a bile: plasma concentration ratio close to unity. The individual values of the concentration ratios and the average rates of change of plasma clearance with bile flow are given in Table III.

The concentrations of sucrose and mannitol in liver water appear in Table IV together with the tissue concentrations of $\mathrm{Na}^{+}, \mathrm{K}^{+}$, and ${ }^{131} \mathrm{I}$-labeled albumin in five additional estrone-treated rats and five controls. Livers from estrone-treated rats contained less sucrose relative to plasma than controls and had a slightly higher fractional water content. Estrone had no significant effect on the hepatic content of albumin, $\mathrm{Na}^{+}, \mathrm{K}^{+}$, or mannitol, nor were there discernible relations between any of these measurements and bile flow. By using the plasma equivalent space occupied by albumin as a measure of extracellular fluid in the liver, the ratio of sucrose concentrations in intracellular water and plasma were estimated from the relation,

$$
[\mathrm{S}]_{\mathrm{c}} /[\mathrm{S}]_{\mathrm{p}}=\frac{[\mathrm{S}]_{\mathrm{l}} /[\mathrm{S}]_{\mathrm{p}}-[\mathrm{A}]_{\mathrm{l}} /[\mathrm{A}]_{\mathrm{p}}}{1-[\mathrm{A}]_{\mathrm{l}} /[\mathrm{A}]_{\mathrm{p}}}
$$

in which [S] and [A] refer to the concentrations of sucrose and albumin, respectively, and the subscripts, c, 1 , and $\mathrm{p}$, designate intracellular water, total liver water, and plasma. Bile: cell $\mathrm{H}_{2} \mathrm{O}$ concentration ratios for sucrose calculated from this estimate of intracellular sucrose and the measured concentration in bile are given in Table IV. Bile from control rats always contained less sucrose than intracellular water, but at low rates of 
TABLE III

Mannitol Excretion

\begin{tabular}{|c|c|c|c|c|c|}
\hline & \multicolumn{2}{|c|}{$\begin{array}{l}\text { Bile: plasma concen- } \\
\text { tration ratio }\end{array}$} & \multicolumn{2}{|c|}{$\begin{array}{l}\text { Change in bile flow with } \\
\text { dehydrocholate }\end{array}$} & \multirow{2}{*}{$\begin{array}{l}\text { Clearance } \\
\text { slope, } \\
\Delta \mathrm{C} / \Delta \mathrm{F}^{*}\end{array}$} \\
\hline & $\begin{array}{l}\text { Spontaneous } \\
\text { flow }\end{array}$ & Choleresis & $\mu 1 \min ^{-1}$ & $\mu l \min ^{-1} g^{-1}$ & \\
\hline \multirow[t]{5}{*}{ Control } & 0.92 & 0.82 & 25.1 & 3.8 & 0.78 \\
\hline & 0.95 & 0.82 & 23.2 & 3.8 & 0.77 \\
\hline & 0.94 & 0.78 & 17.4 & 2.9 & 0.70 \\
\hline & 1.02 & 0.79 & 23.4 & 3.9 & 0.69 \\
\hline & 0.94 & 0.67 & 32.3 & 5.7 & 0.59 \\
\hline Mean & 0.96 & 0.77 & 24.3 & 4.0 & 0.71 \\
\hline $95 \%$ c.1. & 0.05 & 0.07 & 6.6 & 1.3 & 0.09 \\
\hline \multirow[t]{6}{*}{ Estrone } & 1.02 & 1.08 & 16.7 & 2.4 & 1.10 \\
\hline & 1.09 & 0.99 & 19.2 & 2.3 & 0.93 \\
\hline & 1.05 & 0.95 & 13.4 & 2.0 & 0.90 \\
\hline & 0.96 & 1.06 & 15.6 & 1.9 & 1.10 \\
\hline & 1.01 & 1.17 & 14.6 & 1.9 & 1.23 \\
\hline & 1.03 & 0.93 & 15.1 & 2.4 & 0.89 \\
\hline Mean & 1.03 & 1.03 & 15.7 & 2.2 & 1.03 \\
\hline $95 \%$ c.1. & 0.05 & 0.09 & 2.1 & 0.2 & 0.15 \\
\hline \multicolumn{6}{|l|}{ Difference } \\
\hline |Mean| & 0.07 & 0.26 & 8.6 & 1.8 & 0.32 \\
\hline $99 \%$ c.i. & NS & 0.15 & 7.6 & 1.4 & 0.23 \\
\hline
\end{tabular}

c.i. $=$ confidence interval; NS $=$ not significant $(\mid$ mean $\mid<$ c.i. $)$.

${ }^{*} \mathrm{C}=$ biliary clearance; $\mathrm{F}=$ bile flow.

bile flow biliary sucrose concentration in rats given es- lie between the space for albumin and that for sodium. trone was more than twice the estimated concentration If sodium is used in the present instance, the effect is within liver cells. Although it is not permissible to as- to exaggerate the differences between the concentrations sume that labeled albumin occupied a liver space identi- of sucrose in cellular fluid and bile.

cal to the extracellular fluid volume, the true value must Plasma from the 10 rats given labeled albumin was

TABLE IV

Concentration Ratios

\begin{tabular}{|c|c|c|c|c|c|c|c|c|}
\hline & \multirow{2}{*}{$\begin{array}{l}\text { Liver } \mathrm{H}_{2} \mathrm{O} \text {, } \\
\text { \% liver wt }\end{array}$} & \multicolumn{5}{|c|}{ Liver $\mathrm{H}_{2} \mathrm{O}$ : plasma } & \multirow{2}{*}{$\begin{array}{c}\text { Cell } \mathrm{H}_{2} \mathrm{O} \text { :plasma, } \\
\text { sucrose }\end{array}$} & \multirow{2}{*}{$\begin{array}{c}\text { Bile: cell } \\
\mathrm{H}_{2} \mathrm{O} \text {, } \\
\text { sucrose }\end{array}$} \\
\hline & & Sucrose & Albumin & Mannitol & $\mathrm{Na}$ & $\mathbf{K}$ & & \\
\hline \multicolumn{9}{|l|}{ Control } \\
\hline Mean & 71.6 & 0.39 & 0.14 & 1.06 & 0.27 & 23 & 0.29 & 0.52 \\
\hline $95 \%$ c.i. & 0.4 & 0.02 & 0.01 & 0.06 & 0.09 & 8 & 0.03 & 0.09 \\
\hline $\mathrm{n}$ & 20 & 10 & 5 & 5 & 5 & 5 & 10 & 10 \\
\hline \multicolumn{9}{|l|}{ Estrone } \\
\hline Mean & 73.0 & 0.34 & 0.14 & 1.09 & 0.27 & 27 & 0.24 & 2.6 \\
\hline $95 \%$ c.i. & 0.3 & 0.03 & 0.01 & 0.06 & 0.03 & 4 & 0.03 & 0.6 \\
\hline $\mathrm{n}$ & 22 & 11 & 5 & 6 & 5 & 5 & 11 & 11 \\
\hline \multicolumn{9}{|l|}{ Difference } \\
\hline $\mid$ Mean $\mid$ & 1.4 & 0.05 & 0 & 0.03 & 0 & 4 & 0.05 & 2.1 \\
\hline $99 \%$ c.i. & 0.6 & 0.04 & NS & NS & NS & NS & 0.05 & 0.7 \\
\hline
\end{tabular}

c.i. $=$ confidence interval; NS $=$ not significant $(\mid$ mean $\mid<c . i.) ; n=$ number of experiments. 
used to measure plasma volume, direct reacting and total bilirubin, glutamic-oxalacetic transaminase, and alkaline phosphatase. No effect of estrone treatment was detected by any of these except for small differences in plasma volume and alkaline phosphatase. Mean plasma volume was $4.0 \pm 0.7 \%$ of body weight in estrone-treated rats and $3.4 \pm 0.3 \%$ in controls $(P<0.05)$. Mean plasma alkaline phosphatase was $2.3 \pm 0.7$ units in rats receiving estrone and $1.4 \pm 0.5$ in controls $(P<0.05)$. Estrone produced no change in the $\mathrm{Na}^{+}$or $\mathrm{K}^{+}$concentration of either plasma or bile.

The livers from five rats given estrone were compared by light microscopy with the livers of five controls. Numbered sections were examined independently by a pathologist ${ }^{1}$ who had no knowledge of the code. Apart from slightly larger liver cell nuclei in the estrone-treated group, no differences were found. Specifically none of the livers showed necrosis, inflammation, fatty metamorphosis, or morphologic evidence of cholestasis.

\section{DISCUSSION}

Assumptions. In addition to the main conclusion to be drawn from this study, that estrone increased the permeability of the biliary tree to sucrose and mannitol, it is worthwhile to consider possible interpretations of the findings as they relate to normal bile formation in the rat. The discussion proceeds from assumptions set forth here to avoid repetitive qualification of statements made later.

Previous reports (23-27) have discussed the use of so-called inert solutes to estimate the rate of canalicular bile formation and to detect subsequent modification of this primary secretion by transductular fluid exchange. An assumption common to these earlier studies as well as the current experiments is that a heterogeneous group of lipid-insoluble materials including creatinine, erythritol, mannitol, sucrose, and inulin are restricted as regards the site and mode of exchange between blood and bile. The site of exchange is assumed to be the canaliculus as distinct from interlobular portions of the biliary tree. Transfer is assumed to occur solely by diffusion and solvent flow. While neither of these assumptions is subject to direct verification, they are consistent with earlier demonstrations that inert solute clearance is inversely related to molecular size, directly related to bile salt excretion and to changes in bile flow after bile salt administration, but independent of variations in bile flow produced by secretin. Together with the finding by Wheeler, Ross, and Bradley (27) that mannitol, creatinine, and erythritol may be concentrated in dog bile,

\footnotetext{
${ }^{1}$ Dr. Thomas Kent, Department of Pathology, University of Iowa, College of Medicine.
}

these observations provide strong support for the view that the solutes in question enter canalicular bile passively and are not normally subject to transfer in either direction across the bile ducts or ductules.

Neither the excretion data obtained with BSP and the inert solutes nor the morphologic evidence available by light microscopy provides a firm basis for assigning the estrogen effect to a particular site in the biliary tree. Nevertheless, it is assumed for the present that estrone exerts its effect at the level of the parenchymal liver cell, modifying the normal mechanisms by which the test substances enter bile, rather than by opening up new pathways for solute transfer downstream. Inasmuch as bile flow appears largely determined by active canalicular secretion of bile salts by a mechanisms similar to that for BSP, the effect of estrone in reducing spontaneous bile flow and the choleretic response to dehydrocholate may reasonably be ascribed to the same changes responsible for impaired BSP excretion. On this basis the decrease in bile flow associated with estrone treatment is assumed to reflect diminished canalicular bile production rather than inhibition of distal fluid secretion or enhanced fluid reabsorption. Though less probable, the alternative possibility that estrone exerts its major effect on the ductal or ductular epithelium cannot be dismissed. Dilatation of the canaliculi and attenuation of microvilli seen with the electron microscope in recurrent cholestasis of pregnancy (28) and a similar syndrome associated with oral contraceptives (8), may be seen in cholestasis from a variety of causes, and accordingly do not necessarily indicate a specific effect of estrogen on these structures.

Plasma clearance of sucrose and mannitol. Fig. 5 illustrates the form of theoretical curves relating the canalicular bile: plasma concentration ratio of an inert solute and its plasma clearance to canalicular bile flow. The parametric equations for these curves have been discussed elsewhere in detail. ${ }^{2}$ The features of importance to the present argument are as follows. At low rates of bile flow the concentration ratio and hence the rate of change of clearance approach unity reflecting the approach to diffusion equilibrium between bile and plasma. As flow increases solute transfer is progressively dominated by the convective effect of solvent flow with the result that both curves approach asymptotes along which further increases in solute excretion are mediated solely

\footnotetext{
${ }^{2}$ Wheeler's derivation (27) adapted from Patlak, Goldstein, and Hoffman (29) is an integrated solution of the equations used earlier by Forker (23) based on the work of Renkin (30). The integrated form used here appears in Fig. 5. Despite their possible importance, no consideration is given here to interactions between solutes moving passively or to the possibility that the barrier limiting solute diffusion may be in a series or parallel with, rather than identical to, the barrier which limits convection.
} 

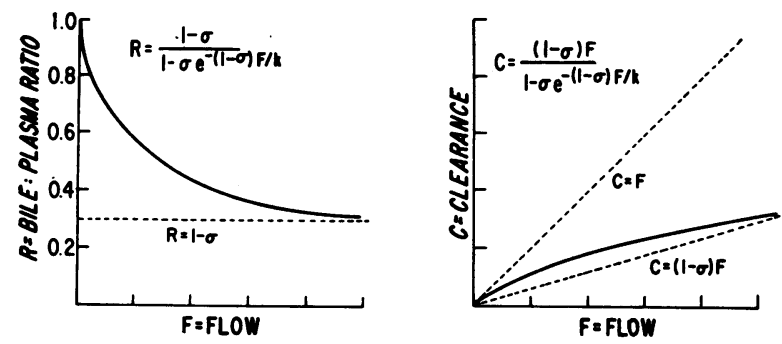

FIGURE 5 Theoretical equations for inert solute excretion. $\mathrm{R}=$ canalicular bile : plasma concentration ratio; $\mathrm{F}=$ canalicular bile flow; $\mathrm{C}=\mathrm{RF}=$ plasma clearance $\mathrm{k}=$ diffusion permeability coefficient; $\sigma=$ Staverman reflection factor.

by filtration. The limiting slope of the clearance curve is the limiting concentration ratio determined by the sieving coefficient (one minus the Staverman reflection factor) of the canalicular membrane. The curves drawn in Fig. 5 are thus examples from families of curves for which the parameters are the diffusion permeability coefficient and the reflection factor.

Comparison of the theoretical curve for the bile: plasma concentration ratio with actual values plotted in Fig. 3 shows that the virtually constant value of sucrose concentration in control rats resembles the curve expected for transport dominated by convection, whereas the flow-dependent decline in concentration observed in rats given estrone suggests an important contribution by diffusion. During rapid bile flow biliary sucrose concentration in rats given estrone approached the concentration in controls suggesting that the differences observed at slower rates of bile flow might be entirely accounted for by a change in diffusion permeability. The success with which the experimental data can be fitted to this hypothesis is indicated in Fig. 6 which illustrates two pairs of theoretical curves drawn to encompass respectively the values obtained in control rats and those given estrone (with one exception). Reasonable agreement between observation and theory is obtained by assuming the same reflection factors for both sets of values but diffusion permeabilities which are from three to nine times higher for estrone-treated rats than for controls.

In considering the possibility that enhanced sucrose clearance is attributable specifically to an increase in the diffusion permeability coefficient as distinct from a change in the reflection factor, it must be remembered that the theoretical equations are derived for canalicular flow, whereas the values actually found may reflect modifications in both flow and sucrose concentration produced by additional fluid secretion or fluid reabsorption in the bile ducts. Provided that estrone does not increase the rate of canalicular bile production, the question of distal fluid exchange cannot alter the conclusion that canalicular permeability increased. It is possible, nevertheless, that the decline in sucrose concentration seen during choleresis was determined, at least partly, by transductular fluid movement rather than by a selective change in diffusion permeability of the canalicular membrane. Consideration of the bile: plasma concentration ratios for mannitol, however, suggests that this alternative explanation is less likely. In rats given estrone the concentration of mannitol in common duct bile was nearly identical to that in plasma. The observed values, therefore, cannot represent dilution of canalicular mannitol by distal fluid secretion. On the other hand, if mannitolfree fluid were being reabsorbed during spontaneous flow, this effect should have been recognized as a higher concentration of mannitol in the bile of estrone-treated rats than in controls. Since this did not occur, it is probable that at rates of bile flow less than the spontaneous rates observed in control animals, mannitol achieved diffusion equilibrium in canalicular bile even without estrone treatment. Owing to the fact that even the normal biliary tree presents relatively little restriction to passage of mannitol, control rats with faster rates of bile flow had mannitol clearance rates equal to or slightly greater than had rats given estrone. A permeability change is apparent, nevertheless, from a comparison of the rates of change of clearance (Fig. 4 and Table III). The rate of change of curvature of the theoretical curve is such that no single pair of values for the reflection factor and the diffusion permeability coefficient can fit both sets of mannitol values. Thus, although the patterns of mannitol clearance do not distinguish between increased solute diffusion and increased solvent drag, they clearly imply that estrone-treated rats presented a more permeable barrier to mannitol excretion than did controls.

Possible pathways for inert solute excretion. Attention has already been drawn (25) to the uncertainty regarding whether inert solutes enter bile by passing between liver cells or whether the normal pathway for excretion is through the cell interior. For small solutes such as mannitol that achieve equilibrium in cell water this distinction is unimportant to the present argument, but for solutes as large as sucrose the interpretation to be made of the concentration in bile depends upon whether it is referred to the concentration in plasma or to the substantially lower concentration within liver cells. This problem assumes special importance in the rats given estrone, because bile from these rats contained more than twice as much sucrose as did intracellular water. If hepatocytes were the only route for sucrose excretion, a steady-state bile: cell $\mathrm{H}_{2} \mathrm{O}$ concentration ratio greater than unity would clearly imply fluid reabsorption from some distal locus in the biliary tree. A corollary would be that mannitol should also be concentrated. Since bile never contained significantly more 
mannitol than did liver cells, the important alternatives are that either a major portion of the sucrose appearing in bile enters by passing between liver cells or that estrone allows mannitol to be passively reabsorbed from the biliary tree. ${ }^{3}$

There is no a priori reason to assume that because sucrose enters liver cells that this is the pathway by which it enters bile. It is possible, therefore, that intracellular sucrose concentration would eventually approach equilibrium with plasma but at a much later time than the concentrations in bile and plasma reach the steadystate. If entry of sucrose into cells were very slow, it might be easy to mistake a slowly rising intracellular concentration for a true steady-state value and thus to overestimate the relevant bile: cell $\mathrm{H}_{2} \mathrm{O}$ concentration ratio. This point should be accessible to verification in the future. Alternatively, if the liver cell is the compartment of origin for the sucrose appearing in bile, the present experiments indicate that at low rates of flow the rat can reabsorb somewhat more than half of the fluid originally produced in the canaliculus. Wheeler et al. (27) have provided convincing evidence that comparable rates of reabsorption can occur in the chronically cholecystectomized dog in the absence of exogenous estrogen. The fact that a smaller solute, mannitol, was not also concentrated by this process in the rat could mean that the permeability changes effected by estrone involve the duct epithelium to some extent as well as the canalicular membrane. It seems unlikely, however, that the distal biliary epithelium would allow unrestricted reabsorption of mannitol yet present an effective barrier to sucrose.

In any event, it is worth emphasizing that at comparable rates of bile flow, rats given estrone excreted more sucrose and mannitol than did controls regardless of whether the compartment of origin is taken to be plasma or intracellular fluid. The inference that estrone brought about an important change in the permeability of the biliary tree, therefore, depends fundamentally only on the assumption that bile production at the site of inert solute entry was not greater in estrone-treated rats than in controls. The mechanism by which estrone produces its effect, whether directly or through the mediation of other hormones, remains to be clarified. Small but significant differences were noted in body weight, liver weight, and total liver water, but these changes were not associated with alterations in the elec-

\footnotetext{
${ }^{3}$ The remaining possibiliites, that sucrose is actively secreted into bile or that it enters an intracellular fluid compartment that comprises but a small fraction of total cell $\mathrm{H}_{2} \mathrm{O}$, are considered remote but cannot be rigorously excluded. It is clear from earlier chromatographic studies (25, 26) that radioactive metabolites of sucrose do not appear in bile or plasma. In the present study this finding has been confirmed for rats given estrone.
}

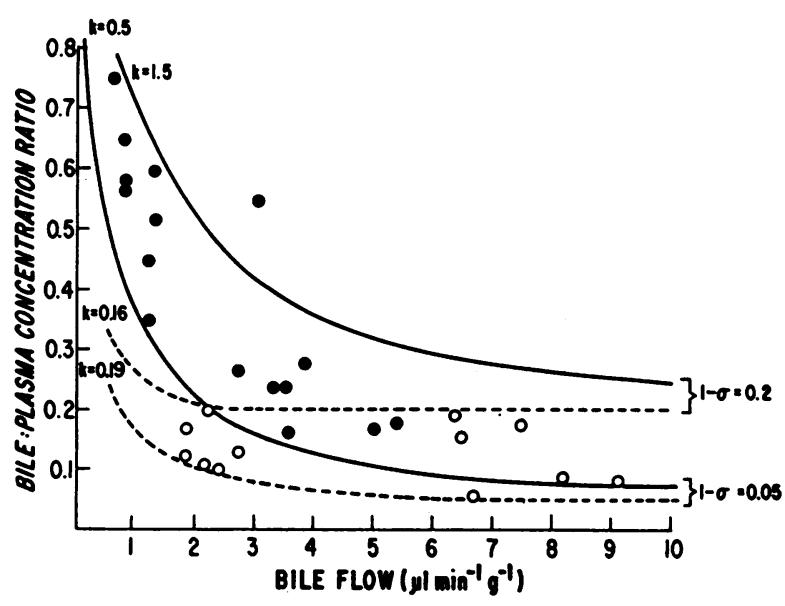

Figure 6 Theoretical curves drawn to enclose sucrose concentration ratios from Fig. 2 using arbitrarily chosen values of the reflection factor. Estrone ( $\bullet$, solid curves); control ( $O$, dashed curves).

trolyte composition of liver tissue or the volume of extracellular fluid as estimated by the albumin space or the sodium space. As reported by others (10) even the very large doses of estrogen employed here did not result in morphologic changes which could explain the striking alterations in bile formation.

$B S P$ transport. In view of the fact that estrone increased the passive permeability of the biliary tree to sucrose and mannitol, it is probable that a similar change occurred with respect to BSP. While it is unlikely that this phenomenon could entirely account for the changes in net BSP transport, the large concentration gradient developed between blood and bile by the active transport of this dye virtually demand that some BSP move passively across a barrier which permits an appreciable diffusion of sucrose. In considering the possibility that an increase in permeability to BSP may be an important determinant of the changes in BSP removal, it must be remembered that diffusion of BSP from bile to blood though possibly favored by an electrical gradient, is presumably opposed in the canaliculus by solvent flow in the opposite direction. The relative importance of these opposing forces and their resultant effect on net BSP transport cannot as yet be decided. Among recent reports (31-33) that BSP excretion can be increased substantially by increasing canalicular flow, one (32) has been interpreted to mean that an appreciable diffusion of BSP may occur normally. Others (33) have reported that BSP excretion is flow-dependent only at high plasma levels of BSP, a finding more in keeping with the suggestion of O'Maille, Richards, and Short (31) that for a given rate of canalicular bile flow maximum dye excretion is limited by the absolute concentration in bile 
rather than by the gradient from bile to blood or from bile to the cell interior.

Earlier reports $(4,5,10,13,15,34)$ of the deleterious effect of pregnancy or exogenous estrogens on BSP disposal have suggested a primary defect involving the final rate-limiting step in the transport sequence without a change in the capacity of liver cells to conjugate BSP with glutathione. There are conflicting reports $(4,5$, $10,34)$ about changes, if any, in the dual processes of uptake and intracellular accumulation as defined by the relative storage capacity of Wheeler et al. $(35,36)$. All of these studies appear to have been performed with doses of BSP in excess of those required to achieve maximum BSP excretion. If BSP diffusion occurs, however, its contribution to the deficit in net transfer must be greater at low plasma levels than when active transport is saturated. This minimum condition is met, since estrone causes pronounced inhibition of BSP transport when the excretion rate is substantially less than that which the liver can perform. A number of other factors, not considered here, require further study, however, before the relative importance of passive BSP transfer can be determined. These include in addition to the effect of canalicular bile flow and the choleretic action of BSP itself, the possible influence of estrogens on hepatic blood flow and cellular uptake, as well as the appearance in bile of several conjugates of BSP, each of which may have somewhat different physical characteristics.

The present results do measure one additional parameter of the system which may be important. Kreek et al. (14) have reported that in rats ethinyl estradiol profoundly delays the appearance of BSP at the common duct. In the experiments reported here the initial appearance of BSP was somewhat later in estrone-treated rats than in controls, but this change was too small to be verified statistically and much less than that reported by Kreek. In any event, a more reliable index of the time relationships is provided by the mean excretory transit time, i.e., the average time taken by BSP to traverse the liver cells and the biliary tree. Though not mentioned in Kreek's report, this time can be estimated from the curves in Fig. 1 by methods presented elsewhere (37). Mean values obtained after small corrections for delay in the common duct cannula were $16 \mathrm{~min}$ and $17 \mathrm{~min}$ for estrone-treated rats and controls respectively. Since the delay in BSP excretion is largely determined by the size of the intracellular pool relative to the final excretion rate, the present results suggest that this ratio was similar in both estrone-treated rats and controls, an unexpected finding if the effect of estrone were limited to inhibition of the active transport system responsible for moving dye from the cell into bile but consistent with the view that BSP may move from canalicular bile back to blood along a different pathway.

\section{ACKNOWLEDGMENTS}

Technical assistants were Mrs. Phyllis Anderson and Mrs. Kathleen Maddox.

This work was supported by U. S. Public Health Service Grant Am-09892.

\section{REFERENCES}

1. Haemmerli, U. P. 1967. Jaundice During Pregnancy. Springer-Verlag New York Inc., New York.

2. Sherlock, S. 1968. Jaundice in pregnancy. Brit. Med. Bull. 24: 39.

3. Kreek, M. J., E. Weser, M. H. Sleisenger, and G. H. Jeffries. 1967. Idiopathic cholestasis of pregnancy. $N$. Eng. J. Med. 277: 1391.

4. Combes, B., H. Shibata, R. Adams, B. D. Mitchell, and V. Trammell. 1963. Alterations in sulfobromophthalein sodium-removal mechanisms from blood during normal pregnancy. J. Clin. Invest. 42: 1431.

5. Tindall, V. R., and J. M. Beazley. 1965. An assessment of changes in liver function during normal pregnancyusing a modified bromsulphthalein test. J. Obstet. Gynaecol. Brit. Empire. 72: 717.

6. Orellana-Alcalde, J. M., and J. P. Dominguez. 1966. Jaundice and oral contraceptive drugs. Lancet. 11: 1278.

7. Eisalo, A., P. A. Jarvinen, and T. Luukkainen. 1965 Liver-function tests during intake of contraceptive tablets in pre-menopausal women. Brit. Med. J. 1: 1416.

8. Larsson-Cohn, U., and U. Stenram. 1967. Liver ultrastructure and function in icteric and non-icteric women using oral contraceptive agents. Acta Med. Scand. 181: 257.

9. Boake, W. C., S. G. Schade, J. F. Morrissey, and F. Schaffner. 1965. Intrahepatic cholestatic jaundice of pregnancy followed by Enovid-induced cholestatic jaundice. Ann. Intern. Med. 63: 302.

10. Mueller, M. N., and A. Kappas. 1964. Estrogen pharmacology. I. The influence of estradiol and estriol on hepatic disposal of sulfobromophthalein (BSP) in man. J. Clin. Invest. 43: 1905.

11. Kottra, J., and A. Kappas. 1967. Steroid effects on hepatic function: recent observations. Annu. Rev. Med. 18: 325

12. Kappas, A. 1968. Studies in endocrine pharmacology. Biologic actions of some natural steroids on the liver. N. Eng. J. Med. 278: 378.

13. Gallagher, T. F., M. N. Mueller, and A. Kappas. 1966. Estrogen pharmacology. IV. Studies on the structural basis for estrogen-induced impairment of liver function. Medicine. 45: 471.

14. Kreek, M. J., R. E. Peterson, M. H. Sleisenger, and G. H. Jeffries. 1967. Influence of ethinyl estradiol-induced cholestasis on bile flow and biliary excretion of estradiol and bromosulfophthalein by the rat. J. Clin. Invest. 46: 1080 .

15. Kottra, L. L., and A. Kappas. 1966. Estrogen pharmacology. III. Effect of estradiol on plasm disappearance rate of sulfobromophthalein in man. Arch. Intern. Med. 117: 373.

16. Bray, G. A. 1960. A simple efficient liquid scintillator for counting aqueous solutions in a liquid scintillation counter. Anal. Biochem. 1: 279.

17. Seligson, D., J. Marino, and E. Dodson. 1957. Determination of sulfobromophthalein in serum. Clin. Chem. 3: 638 . 
18. Malloy, H. T., and K. A. Evelyn. 1937. The determination of bilirubin with the photoelectric colorimeter. $J$. Biol. Chem. 119: 481.

19. Reitman, S., and S. Frankel. 1957. Colorimetric method for the determination of serum glutamic oxalacetic and glutamic pyruvic transaminases. Amer. J. Clin. Pathol. 28: 56.

20. Bessey, O. A., O. H. Lowry, and M. J. Brock. 1946. A method for rapid determination of alkaline phosphatase with five cubic millimeters of serum. J. Biol. Chem. 164: 321.

21. Natrella, M. G. 1963. Experimental Statistics. U. S. Government Printing Office, Washington, D. C.

22. Klaassen, C. D., and G. L. Plaa. 1967. Species variation in metabolism, storage, and excretion of sulfobromophthalein. Amer. J. Physiol. 213: 1322.

23. Forker, E. L. 1967. Two sites of bile formation as determined by mannitol and erythritol clearance in the guinea pig. J. Clin. Invest. 46: 1189.

24. Forker, E. L., T. Hicklin, and H. Sornson. 1967. The clearance of mannitol and erythritol in rat bile. Proc. Soc. Exp. Biol. Med. 126: 115.

25. Forker, E. L. 1968. Bile formation in guinea pigs: analysis with inert solutes of graded molecular radius. Amer. J. Physiol. 215: 56.

26. Schanker, L. S., and C. A. M. Hogben. 1961. Biliary excretion of inulin, sucrose, and mannitol: analysis of bile formation. Amer. J. Physiol. 200: 1087.

27. Wheeler, H. O., E. D. Ross, and S. E. Bradley. 1968. Canalicular bile production in dogs. Amer. J. Physiol. 214: 866

28. Eliakim, M., E. Sadovsky, O. Stein, and Y. G. Shenkar. 1966. Recurrent cholestatic jaundice of pregnancy. Arch. Intern. Med. 117: 696.
29. Patlak, C. S., D. A. Goldstein, and J. F. Hoffman. 1963. The flow of solute and solvent across a two-membrane system. J. Theor. Biol. 5 : 426.

30. Renkin, E. M. 1954. Filtration, diffusion, and molecular sieving through porous cellulose membranes. J. Gen. Physiol. 38: 225.

31. O'Maille, E. R. L., T. G. Richards, and A. H. Short. 1966. Factors determining the maximal rate of organic anion secretion by the liver and further evidence on the hepatic site of action of the hormone secretin. J. Physiol. 186: 424.

32. Ritt, D. J., and B. Combes. 1967. Enhancement of apparent excretory maximum of sulphobromophthalein sodium (BSP) by taurocholate and dehydrocholate. J. Clin. Invest. 46: 1108

33. Gronwall, R., and C. E. Cornelius. 1966. Biliary excretion of sulfobromophthalein in sheep. Fed. Proc. $25: 576$.

34. Kleiner, G. J., L. Kresch, and I. M. Arias. 1965. Studies of hepatic excretory function. II. The effect of norethynodrel and mestranol on bromosulfalein sodium metabolism in women of childbearing age. N. Eng. J. Med. 273: 420.

35. Wheeler, H. O., R. M. Epstein, R. R. Robinson, and E. S. Snell. 1960. Hepatic storage and excretion of sulfobromophthalein sodium in the dog. J. Clin. Invest. 39: 236.

36. Wheeler, H. O., J. I. Meltzer, and S. E. Bradley. 1960. Biliary transport and hepatic storage of sulfobromophthalein sodium in the unanesthetized dog, in normal man, and in patients with hepatic disease. J. Clin. Invest. 39: 1131.

37. Forker, E. L., and C. A. M. Hogben. 1967. Diodrast transit time in guinea pig biliary tree. Amer. J. Physiol. 212: 104. 